\title{
Time-averaged albumin predicts the long-term prognosis of IgA nephropathy patients who achieved remission
}

Zhaohui $\mathrm{Ni}^{\dagger}$, Yanhong Yuan ${ }^{\dagger}$, Qin Wang, Liou Cao, Xiajing Che, Minfang Zhang, Yuanyuan Xie, Chaojun Qi and Shan Mou*

\begin{abstract}
Background: Primary IgA nephropathy (IgAN) is the most common form of idiopathic glomerulonephritis worldwide. Although most patients are able to achieve remission with the current therapy, a large number of patients will still progress to end-stage renal disease. This study aimed to evaluate kidney disease progression and the risk factors for progression in IgAN patients who achieved remission.

Methods: Patients from a prospective database with IgAN were included in this study. All the subjects had achieved a complete remission (CR) or partial remission (PR) following 6 months of therapy. Renal survival and the relationship between the clinical parameters and composite renal outcomes were assessed.

Results: The study comprised 878 IgAN patients recruited between January 2005 and December 2010. Overall, 632 patients were enrolled in this study. The data from the 369 patients who achieved remission were analyzed; the mean follow-up time was 49 months. The median serum creatinine ( $\mathrm{SCr}$ ) concentration at baseline was $91.3 \mu \mathrm{mol} / \mathrm{L}$, and the time-averaged creatinine (TA-SCr) was $91.8 \mu \mathrm{mol} / \mathrm{L}$. The mean serum albumin (ALB) level at baseline was $39.4 \mathrm{~g} / \mathrm{L}$, and the time-averaged serum albumin (TA-ALB) was $42.1 \mathrm{~g} / \mathrm{L}$. Multivariate Cox regression analyses revealed that the TA-ALB and TA-SCr levels were independently associated with the composite renal outcome. The patients with a TA-SCr value $>120 \mu \mathrm{mol} / \mathrm{L}$ and a TA-ALB level $<38 \mathrm{~g} / \mathrm{L}$ were less likely to recover from renal progression.

Conclusion: The strong predictive relationship of low TA-ALB and high TA-SCr levels with progression observed in this study suggests that TA-ALB may serve as a marker of the long-term renal prognosis of IgAN patients who have achieved remission.
\end{abstract}

Keywords: IgA nephropathy, Remission, Renal progression, Risk factor, Time-averaged serum albumin

\section{Introduction}

Primary IgA nephropathy (IgAN) is a very common idiopathic glomerulonephritis (GN) throughout the world [1], especially in China, where IgAN accounts for $58.2 \%$ of the GN cases [2]. Studies have confirmed that 1\%-2\% of IgAN patients will develop end stage renal disease (ESRD) within 1 year of diagnosis [3,4], and approximately $40 \%$ of patients will ultimately develop ESRD within 20 years $[5,6]$. A wide variety of treatments have

\footnotetext{
*Correspondence: shanmou_renji@126.com

${ }^{\dagger}$ Equal contributors

Department of Nephrology, Molecular Cell Lab for Kidney Disease, Ren Ji

Hospital, School of Medicine, Shanghai Jiao Tong University, 1630 Dongfang Road, Shanghai 200127, China
}

(C) 2014 Ni et al.; licensee BioMed Central Ltd. This is an Open Access article distributed under the terms of the Creative Commons Attribution License (http://creativecommons.org/licenses/by/4.0), which permits unrestricted use, distribution, and reproduction in any medium, provided the original work is properly credited. The Creative Commons Public Domain Dedication waiver (http://creativecommons.org/publicdomain/zero/1.0/) applies to the data made available in this article, unless otherwise stated.

been attempted to slow the progression of IgAN. Based on the evidence, most treatment guidelines for IgAN recommend optimal blood pressure control and suggest adding steroids for those patients with persistent proteinuria, regardless of supportive therapy [7]. However, few studies have evaluated the progression of and risk factors for the progression of IgAN under the current treatment regimens.

Several clinical researchers [8-10] have confirmed the prognostic value of certain clinical and biochemical parameters for the outcomes of patients with IgAN. Systolic hypertension, massive proteinuria, renal impairment, serum albumin (ALB) level $[11,12]$, and severe histological findings on a renal biopsy have been reported as risk 
factors for ESRD [13]. Other risk factors regarding the clinical course [5,14-18] are numerous and controversial in the literature, including age at disease onset, gender, obesity, hemoglobin levels, hypertriglyceridemia, inappropriate lifestyles, geography, and various immunogenetic markers. One of the problems in the field is that previous studies have consistently identified various clinicopathologic parameters at the time of diagnosis, but the patients were not followed long-term in most cases. By analyzing a large number of patients, this study aimed to clarify the long-term renal survival and related risk factors for progression in IgAN patients who achieved remission with the current therapy.

\section{Materials and methods Subjects}

The study comprised 878 IgAN patients recruited between January 2005 and December 2010 from the Department of Nephrology, Ren Ji Hospital, Shanghai, China. All the patients had definitive pathological data with predominant (at least 1+) mesangial staining for IgA according to immunofluorescence staining and electrondense deposits within the mesangium according to electron microscopy analysis. Patients who presented at younger than 18 years of age $(n=30)$, were pregnant $(n=3)$, had acute kidney failure $(n=12)$, had less than 36 months of follow-up $(n=160)$, had systemic inflammation such as Henoch-Schönlein purpura $(n=6)$, or had chronic advanced liver disease $(n=35)$ were excluded. A total of 632 patients were included. The study was approved by the Ethics Committee of Ren Ji Hospital, and all the participants gave written informed consent. All the kidney biopsy slides were reviewed by an experienced renal pathologist.

Only those subjects in whom the treatment response evaluated at 6 months after the initiation of therapy met the criteria for a complete remission (CR) or partial remission (PR) were included in the present study. A CR was defined as the absence of proteinuria, the normalization of all biochemical findings, and a lack of worsening of renal function. A PR was defined as a $>50 \%$ reduction in proteinuria from baseline. No response (NR) was defined as a $<50 \%$ reduction in proteinuria or an increase in proteinuria, with or without renal deterioration. In the end, 369 patients who met the remission criteria were enrolled.

At the end of the follow-up, the estimated glomerular filtration rate (eGFR) values were evaluated. The primary outcome was a doubling of the baseline serum creatinine (SCr); secondary outcomes included ESRD and death. Patients were classified with progression when their eGFR values decreased (below the normal range) $\geq 5 \mathrm{ml} /$ $\mathrm{min} / 1.73 \mathrm{~m}^{2} /$ year or reached the endpoint during the follow-up period. The patients who stabilized or had a slower decrease in the eGFR were considered as nonprogression patients. Among the 369 remission patients,
61 were progression patients, and 308 subjects were non-progression patients (Figure 1).

\section{Clinical, biochemical and histopathological data collection} The patients had regular follow-up visits at intervals of at least 3-6 months. All the data were collected prospectively. The baseline clinical and demographic data were recorded at the time of the renal biopsy. The demographic data included age and gender. The clinical parameters included systolic blood pressure (SBP), diastolic blood pressure (DBP), blood erythrocytes (RBC), blood leukocytes (WBC), thrombocytes (PLT), hemoglobin ( $\mathrm{Hb}), \mathrm{SCr}$, serum uric acid (UA), blood urea nitrogen (BUN), ALB, glutamic-pyruvic transaminase (ALT), glutamic-oxaloacetic transaminase (AST), triglyceride levels (TG), serum total cholesterol levels (TC), high-density lipoprotein (HDL), low-density lipoprotein (LDL), the erythrocyte sedimentation rate (ESR), complement 3 (C3) levels, serum immunoglobulin (IgA, IgG, IgM) levels, 24-h urinary protein excretion (UPE), hematuria (uRBC/HP), and the eGFR at the diagnosis of IgAN and during the follow-up.

The eGFR was calculated using the Modification of Diet in Renal Disease (MDRD) study equation: eGFR ( $\mathrm{ml} / \mathrm{min} /$ $\left.1.73 \mathrm{~m}^{2}\right)=1.8 \times[\mathrm{SCr}(\mathrm{mg} / \mathrm{dl})]^{-1.154} \times(\text { age })^{-0.203} \times(0.742$ if female) [19]. Chronic kidney disease (CKD) was classified based on the Kidney Disease Outcomes Quality Initiative (K/DOQI) practice guidelines.

For each patient, proteinuria was measured via the UPE. An average UPE was determined for each 3-month block during the follow-up; the average of the UPE values for every 3-month period was represented by the time-averaged UPE (TA-UPE) [20]. The time-averaged serum albumin (TA-ALB), time-averaged serum creatinine (TA-SCr), timeaveraged blood urea nitrogen (TA-BUN), and time-averaged eGFR (TA-eGFR) values were calculated using the same method as that used for the TA-UPE.

Most of the patients were treated according to the accepted standards at our center as follows: (1) full doses of ACEis (angiotensin converting enzyme inhibitors) and/or ARBs (angiotensin receptor blockers) were recommended for all the patients with proteinuria or hypertension; (2) steroids were used in cases of massive proteinuria ( $>1 \mathrm{~g} /$ d); and (3) other immunosuppressive agents were considered in patients with impaired kidney function or rapidly progressing kidney function decline (an increase in $\mathrm{SCr}>$ $15 \%$ in the year before entry into the trial) [21]. Renal lesions were graded according to the Lee's classification at the time the database was established [22].

\section{Statistical analyses}

Analyses of the data were carried out using SPSS software (version 13: SPSS, Chicago, IL). For comparison of the continuous variables between the groups, Student's $t$-test was used if the variables had a normal distribution, and a 


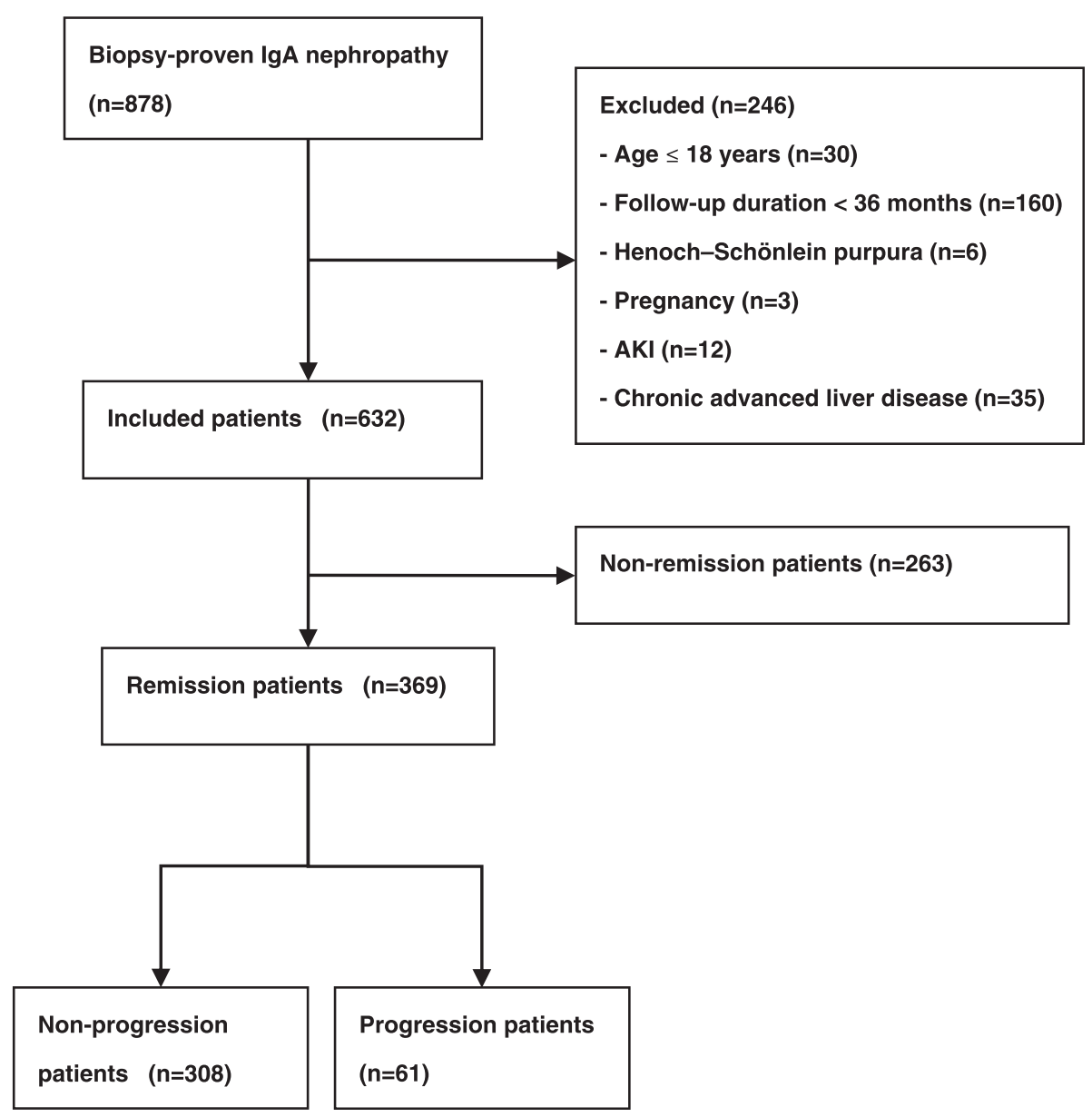

Figure 1 A flow diagram of the study. AKI: Acute kidney injury.

Mann-Whitney $U$-test was used if there was not a normal distribution. The chi squared test was employed for the categorical variables. Cox's proportional hazards models for estimating the hazard ratios and the $95 \%$ confidence intervals $(\mathrm{CI})$ were used to identify the predictive factors for the development of IgAN progression. The multivariate models used a stepwise forward selection procedure based on a likelihood-ratio test with $\mathrm{P}>0.10$ for the removal and $\mathrm{P}<$ 0.05 for the entry of the variables. Receiver operating characteristic curves (ROC) were established to determine the optimal cutoff value of a risk factor for predicting renal progression. In addition, ROC curves were also analyzed when two risk factors were combined. Renal survival was estimated with the Kaplan-Meier method, and comparisons were performed using the log-rank test. The results were reported as the means \pm standard deviation (SD). Values of $P$ less than 0.05 were considered statistically significant.

\section{Results}

Baseline demographic and clinical data

From 2005 to 2010, 878 patients with primary IgAN were recorded in the Registry Database, among whom
246 cases were excluded and 632 cases were included in this study. The data from a total of 369 patients with IgAN who achieved remission 6 months following therapy were utilized in the analyses. The clinical characteristics at baseline and during the follow-up were summarized in Tables 1 and 2. All the subjects were Chinese. There were 184 males and 185 females in the study, and the mean age at biopsy was $37.2 \pm 12.3$ years. The mean SBP and DBP at baseline were $123.8 \pm 15.9 \mathrm{~mm} \mathrm{Hg}$ and $79.3 \pm 9.5 \mathrm{~mm} \mathrm{Hg}$, respectively. The mean eGFR was $83.6 \pm 28.4 \mathrm{ml} / \mathrm{min} /$ $1.73 \mathrm{~m}^{2}$. The median and interquartile range (IQR) values for the initial proteinuria were 2.1 and $1.2-3.2 \mathrm{~g} / \mathrm{d}$, respectively. Moreover, $17 \%$ of the patients had ALB levels less than $35 \mathrm{~g} / \mathrm{L}$, and the mean ALB level was $39.4 \pm 5.5 \mathrm{~g} / \mathrm{L}$. The patients were followed for 49.0 (38.0-65.8 months) months, and 61 of these patients reached the endpoint of the follow-up.

\section{Comparison of the baseline characteristics of the progression and non-progression groups}

We compared the baseline characteristics of the progression and non-progression groups (Table 1). Our data revealed 
Table 1 Baseline clinical characteristics and renal parameters of patients with IgAN

\begin{tabular}{|c|c|c|c|c|}
\hline Characteristics & $\begin{array}{l}\text { Remission patients } \\
(\mathrm{n}=369)\end{array}$ & $\begin{array}{l}\text { Non-progression patients } \\
(\mathrm{n}=308)\end{array}$ & $\begin{array}{l}\text { Progression patients } \\
(\mathrm{n}=61)\end{array}$ & P-value \\
\hline Age (years) & $37.2 \pm 12.3$ & $37.0 \pm 1.7$ & $38.1 \pm 3.9$ & NS \\
\hline Gender: Female n (\%) & $185(50.1)$ & $160(51.9)$ & $25(40.9)$ & NS \\
\hline SBP (mm Hg) & $123.8 \pm 15.9$ & $123.5 \pm 2.3$ & $125.0 \pm 3.7$ & NS \\
\hline $\mathrm{DBP}(\mathrm{mm} \mathrm{Hg})$ & $79.3 \pm 9.5$ & $79.2 \pm 1.4$ & $79.8 \pm 2.8$ & NS \\
\hline $\operatorname{RBC}\left(X 10^{12} / L\right)$ & $4.4 \pm 0.5$ & $4.4 \pm 0.2$ & $4.5 \pm 0.3$ & NS \\
\hline WBC (X 109/L) & $7.2 \pm 1.7$ & $7.0 \pm 0.3$ & $7.8 \pm 0.4$ & NS \\
\hline $\mathrm{Hb} \mathrm{g} / \mathrm{L}$ & $133.7 \pm 18.8$ & $134.3 \pm 2.9$ & $131.3 \pm 5.4$ & NS \\
\hline $\operatorname{PLT}\left(X 10^{9} / \mathrm{L}\right)$ & $209.7 \pm 63.8$ & $215.5 \pm 10.8$ & $191.6 \pm 23.6$ & NS \\
\hline ALB g/L & $39.4 \pm 5.5$ & $39.9 \pm 0.8$ & $37.7 \pm 1.5$ & NS \\
\hline ALT IU/L & $16.0(12.0-20.5)$ & $16.0(13.0-22.0)$ & $15.0(11.0-19.0)$ & NS \\
\hline AST U/L & $19.7 \pm 8.5$ & $20.4 \pm 1.7$ & $17.5 \pm 0.9$ & NS \\
\hline TG mmol/L & $1.6(1.1-2.3)$ & $1.56(1.1-2.4)$ & $1.9(1.3-2.2)$ & NS \\
\hline $\mathrm{TC} \mathrm{mmol} / \mathrm{L}$ & $5.0(4.3-6.0)$ & $4.97(4.3-6.0)$ & $5.1(4.5-5.9)$ & NS \\
\hline $\mathrm{HDL} \mathrm{mmol/L}$ & $1.29 \pm 0.5$ & $1.3 \pm 0.1$ & $1.2 \pm 0.1$ & NS \\
\hline LDL mmol/L & $3.35 \pm 1.7$ & $3.4 \pm 0.3$ & $3.1 \pm 0.2$ & NS \\
\hline FBG mmol/L & $4.9 \pm 0.5$ & $4.93 \pm 0.1$ & $4.8 \pm 0.2$ & NS \\
\hline $\mathrm{SCr} \mu \mathrm{mol} / \mathrm{L}$ & $91.3 \pm 36.4$ & $86.2 \pm 4.7$ & $112.8 \pm 11.9$ & 0.02 \\
\hline BUN mmol/L & $6.1 \pm 2.4$ & $5.8 \pm 0.3$ & $7.7 \pm 0.9$ & 0.03 \\
\hline eGFR $\left(\mathrm{ml} / \mathrm{min} / 1.73 \mathrm{~m}^{2}\right)$ & $83.6 \pm 28.4$ & $87.7 \pm 3.9$ & $66.7 \pm 7.8$ & 0.03 \\
\hline UA $\mu \mathrm{mol} / \mathrm{L}$ & $337.0(280.9-426.5)$ & $327.5(277.4-414.0)$ & $370.0(326.5-514.5)$ & NS \\
\hline Ca mmol/L & $2.3 \pm 0.1$ & $2.3 \pm 0.02$ & $2.3 \pm 0.1$ & NS \\
\hline $\mathrm{P} \mathrm{mmol} / \mathrm{L}$ & $1.2 \pm 0.2$ & $1.23 \pm 0.05$ & $1.2 \pm 0.04$ & NS \\
\hline $\mathrm{ESR} \mathrm{mm} / \mathrm{h}$ & $22.0(10.0-34.0)$ & $22.0(9.0-34.0)$ & $24.0(11.0-33.0)$ & NS \\
\hline $\lg A$ g/L & $2.9 \pm 0.9$ & $2.8 \pm 0.2$ & $3.1 \pm 0.2$ & NS \\
\hline $\operatorname{lgG} \mathrm{g} / \mathrm{L}$ & $12.3 \pm 3.2$ & $12.7 \pm 0.6$ & $11.4 \pm 0.9$ & NS \\
\hline $\operatorname{lgM} \mathrm{g} / \mathrm{L}$ & $1.3 \pm 0.8$ & $1.4 \pm 0.2$ & $1.1 \pm 0.2$ & NS \\
\hline C3 g/L & $1.05 \pm 0.2$ & $1.06 \pm 0.04$ & $1.0 \pm 0.1$ & NS \\
\hline UPE (g/d) & $2.1(1.2-3.2)$ & $1.8(1.2-3.1)$ & $2.4(2.0-3.6)$ & NS \\
\hline URBC /HP & $28.4(7.5-50.0)$ & $29.1(7.2-50.0)$ & $14.0(9.4-29.1)$ & NS \\
\hline \multicolumn{5}{|l|}{ CKD stage $\mathrm{n}(\%)$} \\
\hline Stage 1 & $310(84.0)$ & $264(85.7)$ & $46(75.4)$ & \\
\hline Stage 2 & $37(10.0)$ & $29(9.4)$ & $8(13.1)$ & \\
\hline Stage 3 & $22(6.0)$ & $15(4.9)$ & $7(11.5)$ & \\
\hline Stage 4 & 0 & 0 & 0 & \\
\hline Stage 5 & 0 & 0 & 0 & NS \\
\hline \multicolumn{5}{|c|}{ Renal biopsy Lee's classification n (\%) } \\
\hline Grade I-II & $13(3.5)$ & $13(4.2)$ & 0 & \\
\hline Grade III & $194(52.6)$ & $163(52.9)$ & $31(50.8)$ & \\
\hline Grade IV & $131(35.5)$ & $107(34.7)$ & $24(39.3)$ & \\
\hline Grade V & $31(8.4)$ & $25(8.2)$ & $6(9.9)$ & NS \\
\hline
\end{tabular}

Values are given as the means \pm standard deviation (SD) if the variables showed a normal distribution and as medians (IQR) if the variables did not show a normal distribution; $\mathrm{n}(\%)$ was used for the categorical variables.

SBP: systolic blood pressure; DBP: diastolic blood pressure; RBC: blood erythrocytes; WBC: blood leukocytes; Hb: hemoglobin; PLT: thrombocytes; ALB: serum albumin; ALT: glutamic-pyruvic transaminase; AST: glutamic-oxaloacetic transaminase; TG: triglyceride levels; TC: Serum total cholesterol levels; $\bar{H}$ DL: high density lipoprotein; LDL: low density lipoprotein; FBG: fasting blood glucose; SCr: serum creatinine; BUN: blood urea nitrogen; eGFR: estimated glomerular filtration rate; UA: serum uric acid; Ca: serum calcium levels; P: serum inorganic phosphorus levels; ESR: erythrocyte sedimentation rate; lgA, IgG, IgM: serum immunoglobulin levels; C3: complement 3 levels; UPE: 24-h urinary protein excretion; URBC/HP: hematuria. 
Table 2 Comparison of characteristics between progression and non-progression patients during the follow-up

\begin{tabular}{|c|c|c|c|c|}
\hline Characteristics & $\begin{array}{l}\text { Remission patients } \\
(\mathrm{n}=369)\end{array}$ & $\begin{array}{l}\text { Non-progression patients } \\
(n=308)\end{array}$ & $\begin{array}{l}\text { Progression patients } \\
(\mathrm{n}=61)\end{array}$ & P-value \\
\hline $\mathrm{ALB} \mathrm{g} / \mathrm{L}$ at month 3 & $40.9 \pm 4.9$ & $41.3 \pm 0.6$ & $39.0 \pm 1.7$ & NS \\
\hline ALB g/L at month 6 & $42.9 \pm 4.2$ & $43.5 \pm 0.6$ & $40.5 \pm 1.3$ & 0.02 \\
\hline TA-ALB g/L & $42.1 \pm 3.8$ & $42.7 \pm 0.5$ & $39.4 \pm 1.2$ & 0.01 \\
\hline $\mathrm{SCr} \mu \mathrm{mol} / \mathrm{L}$ at month 3 & $90.2 \pm 35.5$ & $82.7 \pm 3.9$ & $121.6 \pm 13.9$ & 0.01 \\
\hline $\mathrm{SCr} \mu \mathrm{mol} / \mathrm{L}$ at month 6 & $88.2 \pm 37.5$ & $80.3 \pm 4.2$ & $121.3 \pm 14.1$ & 0.002 \\
\hline TA-SCr $\mu \mathrm{mol} / \mathrm{L}$ & $91.8 \pm 46.8$ & $80.5 \pm 4.2$ & $136.7 \pm 21.0$ & 0.002 \\
\hline BUN mmol/L at month 3 & $7.4 \pm 2.9$ & $6.8 \pm 0.3$ & $9.8 \pm 1.1$ & 0.01 \\
\hline BUN mmol/L at month 6 & $6.5 \pm 2.3$ & $6.1 \pm 0.3$ & $8.0 \pm 0.9$ & 0.02 \\
\hline TA-BUN mmol/L & $6.6 \pm 2.2$ & $6.1 \pm 0.2$ & $8.6 \pm 0.9$ & 0.004 \\
\hline eGFR $\left(\mathrm{ml} / \mathrm{min} / 1.73 \mathrm{~m}^{2}\right)$ at month 3 & $85.5 \pm 33.1$ & $90.8 \pm 4.4$ & $63.4 \pm 8.2$ & 0.01 \\
\hline eGFR $\left(\mathrm{ml} / \mathrm{min} / 1.73 \mathrm{~m}^{2}\right)$ at month 6 & $88.9 \pm 33.7$ & $95.1 \pm 4.6$ & $63.1 \pm 7.8$ & 0.003 \\
\hline TA-eGFR $\left(\mathrm{ml} / \mathrm{min} / 1.73 \mathrm{~m}^{2}\right)$ & $88.5 \pm 33.2$ & $95.1 \pm 4.5$ & $61.9 \pm 8.1$ & 0.002 \\
\hline UPE $(\mathrm{g} / \mathrm{d})$ at month 3 & $0.7(0.4-1.3)$ & $0.6(0.2-1.0)$ & $1.3(0.7-2.0)$ & 0.04 \\
\hline UPE $(\mathrm{g} / \mathrm{d})$ at month 6 & $0.4(0.2-0.7)$ & $0.4(0.1-0.7)$ & $0.4(0.2-1.2)$ & NS \\
\hline TA-UPE (g/d) & $1.1(0.6-1.6)$ & $1.0(0.6-1.4)$ & $1.3(1.0-2.1)$ & NS \\
\hline
\end{tabular}

Values are given as means \pm standard deviation (SD) if the variables had a normal distribution and as medians (IQR) if the variables did not have a normal distribution; $\mathrm{n}(\%)$ was used for the categorical variables.

TA-ALB: time-averaged serum albumin; TA-SCr: time-averaged serum creatinine; TA-BUN: time-averaged blood urea nitrogen; TA-eGFR: time-averaged eGFR; TAUPE: time-averaged $24-\mathrm{h}$ urinary protein excretion.

that the patients with renal progression had a worse baseline renal function, as represented by the eGFR $(66.7 \pm 7.8 \mathrm{ml} /$ $\min / 1.73 \mathrm{~m}^{2}$ versus $\left.87.7 \pm 3.9 \mathrm{ml} / \mathrm{min} / 1.73 \mathrm{~m}^{2} ; \mathrm{P}=0.03\right)$, the $\mathrm{SCr}$ level $(112.8 \pm 11.9 \mu \mathrm{mol} / \mathrm{L}$ versus $86.2 \pm 4.7 \mu \mathrm{mol} / \mathrm{L}$; $\mathrm{P}=0.02)$, and the BUN $(7.7 \pm 0.9 \mathrm{mmol} / \mathrm{L}$ versus $5.8 \pm$ $0.3 \mathrm{mmol} / \mathrm{L} ; \mathrm{P}=0.03)$. There were no significant differences in the other baseline characteristics, including gender, age, blood pressure, ALB levels, and so on. The classifications of the renal histopathology were summarized in Table 1, and no significant differences were seen between the progression and non-progression groups.

\section{Comparison of the characteristics of the progression and non-progression groups during the follow-up}

The clinical profiles present during the follow-up after diagnosis were shown in Table 2. The renal function, as represented by the eGFR, SCr and BUN values, was significantly different between the two groups, similar to what was observed at baseline. The level of ALB at 6 months was lower $(40.5 \pm 1.3$ versus $43.5 \pm 0.6 \mathrm{~g} / \mathrm{L} ; \mathrm{P}=0.02)$ in patients in the renal progression group than those in the non-progression group. The median value of the UPE at 3 months after the initial biopsy was higher $[1.3(0.7-2.0) \mathrm{g} / \mathrm{d}$ versus $0.6(0.2-$ 1.0) $\mathrm{g} / \mathrm{d} ; \mathrm{P}=0.04 \mathrm{]}$ in the progression group than in the non-progression group. No significant difference was found in the TA-UPE between the two groups.

The time-averaged characteristics of the two groups were also summarized in Table 2, which indicated that the progressing patients had a lower level of TA-ALB $(39.4 \pm 1.2 \mathrm{~g} /$
$\mathrm{L}$ versus $42.7 \pm 0.5 \mathrm{~g} / \mathrm{L} ; \mathrm{P}=0.01$ ), a lower level of TA-eGFR $\left(61.9 \pm 8.1 \mathrm{ml} / \mathrm{min} / 1.73 \mathrm{~m}^{2}\right.$ versus $95.1 \pm 4.5 \mathrm{ml} / \mathrm{min} /$ $\left.1.73 \mathrm{~m}^{2} ; \mathrm{P}=0.002\right)$, a higher level of TA-SCr $(136.7 \pm$ $21.0 \mu \mathrm{mol} / \mathrm{L}$ versus $80.5 \pm 4.2 \mu \mathrm{mol} / \mathrm{L} ; \mathrm{P}=0.002)$, and a higher level of TA-BUN $(8.6 \pm 0.9 \mathrm{mmol} / \mathrm{L}$ versus $6.1 \pm$ $0.2 \mathrm{mmol} / \mathrm{L} ; \mathrm{P}=0.004)$ than the non-progressing patients.

\section{Predictors of progression in IgAN patients who achieved remission}

Both univariate and multivariate Cox analyses were performed to evaluate the impact of the potential predictors of renal progression. As shown in Table 3, in the univariate analyses, the $\mathrm{SCr}, \mathrm{BUN}$, and eGFR values at the baseline and follow-up time periods, the ALB level at the sixth month, and the TA-ALB were statistically significant. Those factors that were significantly correlated with progression on the basis of the univariate analysis were further evaluated with a multivariate analysis. The results revealed that only the TA-ALB and TA-SCr levels were independently associated with renal progression. The adjusted multivariate Cox analysis model indicated that each $1 \mathrm{~g} / \mathrm{L}$ drop in the TA-ALB level was associated with a $14 \%$ increase in the risk of renal progression.

As mentioned previously, the TA-ALB value was used to quantify the level of ALB during the follow-up of patients with IgAN, and the ROC curves for the TA-ALB were established to determine the optimal cutoff values for predicting a worse outcome (Table 4). The area under the ROC curve (AUC) was 0.82 when the TA- 
Table 3 Factors that were found to affect the long-term prognosis in IgAN patients in the univariate and multivariate COX regression analyses

\begin{tabular}{|c|c|c|c|c|c|c|}
\hline & & nivariate an & & & Multivari & \\
\hline & $\mathrm{HR}$ & $95 \% \mathrm{Cl}$ & $P$ value & $\mathrm{HR}$ & $95 \% \mathrm{Cl}$ & $P$ value \\
\hline ALB g/L at month 6 & 0.86 & $0.76-0.96$ & 0.01 & & & NS \\
\hline TA-ALB g/L & 0.8 & $0.70-0.93$ & 0.002 & 0.86 & $0.75-0.98$ & 0.03 \\
\hline Baseline SCr $\mu \mathrm{mol} / \mathrm{L}$ & 1.02 & $1.01-1.04$ & 0.003 & & & NS \\
\hline $\mathrm{SCr} \mu \mathrm{mol} / \mathrm{L}$ at month 3 & 1.03 & $1.02-1.05$ & $<0.001$ & & & NS \\
\hline $\mathrm{SCr} \mu \mathrm{mol} / \mathrm{L}$ at month 6 & 1.03 & $1.02-1.04$ & $<0.001$ & & & NS \\
\hline $\mathrm{TA}-\mathrm{SCr} \mu \mathrm{mol} / \mathrm{L}$ & 1.02 & $1.01-1.03$ & $<0.001$ & 1.02 & $1.01-1.03$ & $<0.001$ \\
\hline Baseline BUN mmol/L & 1.37 & $1.14-1.65$ & 0.001 & & & NS \\
\hline BUN mmol/L at month 3 & 1.35 & $1.15-1.59$ & $<0.001$ & & & NS \\
\hline BUN mmol/L at month 6 & 1.36 & $1.10-1.69$ & 0.005 & & & NS \\
\hline TA-BUN mmol/L & 1.56 & $1.25-1.94$ & $<0.001$ & & & NS \\
\hline Baseline eGFR (ml/min/1.73 $\left.\mathrm{m}^{2}\right)$ & 0.97 & $0.94-0.99$ & 0.01 & & & NS \\
\hline eGFR $\left(\mathrm{ml} / \mathrm{min} / 1.73 \mathrm{~m}^{2}\right)$ at month 3 & 0.96 & $0.94-0.98$ & 0.004 & & & NS \\
\hline eGFR $\left(\mathrm{ml} / \mathrm{min} / 1.73 \mathrm{~m}^{2}\right)$ at month 6 & 0.96 & $0.93-0.98$ & 0.001 & & & NS \\
\hline TA-eGFR $\left(\mathrm{ml} / \mathrm{min} / 1.73 \mathrm{~m}^{2}\right)$ & 0.96 & $0.93-0.98$ & 0.001 & & & NS \\
\hline UPE $(\mathrm{g} / \mathrm{d})$ at month 3 & 1 & $1.00-1.002$ & 0.003 & & & NS \\
\hline TA-UPE $(g / d)$ & 1 & $1.000-1.002$ & 0.01 & & & NS \\
\hline
\end{tabular}

ALB was combined with the ALB value at baseline, at the third month and at the sixth month, indicating that the TA-ALB had a high diagnostic accuracy for an unfavorable renal outcome (sensitivity $90 \%$, specificity $83 \%$ ).

Based on the Kaplan-Meier analyses, the actual renal survival according to the estimated 36-month risk was plotted in Figures 2 and 3. The optimal cutoff for TAALB was $38 \mathrm{~g} / \mathrm{L}$, indicating that the relationship between the TA-ALB values and renal outcomes was dramatically altered at levels as low as $38 \mathrm{~g} / \mathrm{L}$. Those with $\mathrm{SCr}$ levels $>120 \mu \mathrm{mol} / \mathrm{L}$ at baseline, the third month, and the sixth month and ALB levels $<39 \mathrm{~g} / \mathrm{L}$ at the sixth month had an actual cumulative incidence of reaching the primary endpoint.

\section{Discussion}

IgAN is a progressive disease that is characterized by highly variable clinical courses and outcomes [3,23-25]. Although numerous long-term renal survival analyses of patients with IgAN have been published [4,5,16,26,27], few studies have calculated the long-term renal outcomes of Chinese patients, especially those patients who achieve remission after treatment. Nearly all of the patients received RAS inhibitors. Steroids were considered in patients with UPE $>1 \mathrm{~g} / \mathrm{d}$, and other immunosuppressive agents were considered in patients with rapidly progressing renal function decline. Proteinuria declined by approximately $50 \%$, and blood pressure was well controlled among the patients treated with our current therapy

Table 4 Diagnostic performance of ALB for the identification of IgAN progression according to the ROC curve

\begin{tabular}{|c|c|c|c|c|c|c|}
\hline Characteristic & $\begin{array}{l}\text { Area under the } \\
\text { curve (AUC) }\end{array}$ & $95 \% \mathrm{Cl}$ of $\mathrm{AUC}$ & $P$ value & Cut-off value & Sensitivity & Specificity \\
\hline \multicolumn{7}{|l|}{ One characteristic } \\
\hline ALB at month 6 & 0.72 & $0.55-0.89$ & 0.02 & 41.35 & 0.75 & 0.74 \\
\hline TA-ALB & 0.76 & $0.59-0.93$ & 0.01 & 40.89 & 0.8 & 0.7 \\
\hline \multicolumn{7}{|l|}{ Two characteristics combined } \\
\hline Baseline ALB combined with TA-ALB & 0.77 & $0.62-0.93$ & 0.01 & & 0.8 & 0.74 \\
\hline ALB at month 3 combined with TA-ALB & 0.82 & $0.65-1.00$ & 0.001 & & 0.9 & 0.8 \\
\hline ALB at month 6 combined with TA- ALB & 0.77 & $0.60-0.94$ & 0.01 & & 0.8 & 0.67 \\
\hline \multicolumn{7}{|l|}{ Four characteristics combined } \\
\hline $\begin{array}{l}\text { Baseline ALB combined with ALB at month } \\
3 \text {, ALB at month } 6 \text {, and TA-ALB }\end{array}$ & 0.83 & $0.68-0.96$ & 0.001 & & 0.9 & 0.83 \\
\hline
\end{tabular}



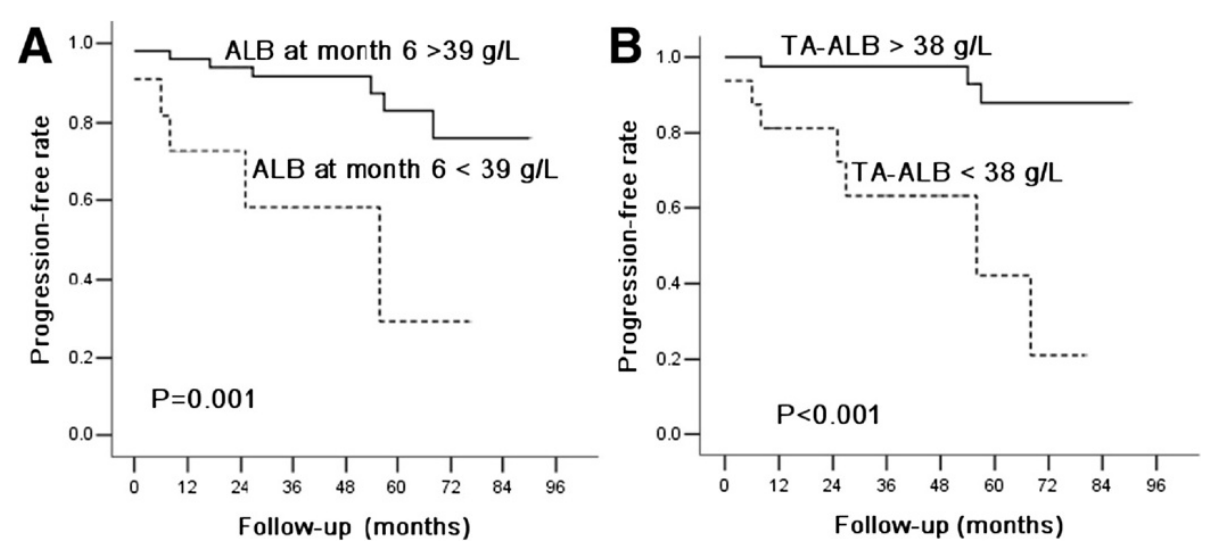

Figure 2 Kaplan-Meier plots of the renal progression-free rates according to the ALB levels during the long-term follow-up. (A) ALB levels at month 6, (B) TA-ALB levels. Patients with a ALB level at month $6 \mathrm{gf}<39 \mathrm{~g} / \mathrm{L}$ or TA-ALB $<38 \mathrm{~g} / \mathrm{L}$ had significantly shorter progression-free times $(P<0.05)$.

regimen. In this large prospective cohort study with more than 360 patients, we evaluated renal progression and the risk factors for renal progression with the current therapy regimen.

Although proteinuria is a known risk factor for the progression of IgAN $[13,20,28,29]$, many important questions regarding the role of proteinuria in the prognosis of IgAN remain. In particular, the timing of the measurements requires clarification. Some studies have proven that UPE at diagnosis is often not a predictor of the outcome according to a Cox regression analysis [25,26]; instead, UPE at 1 year or later may better indicate the prognosis [26]. In
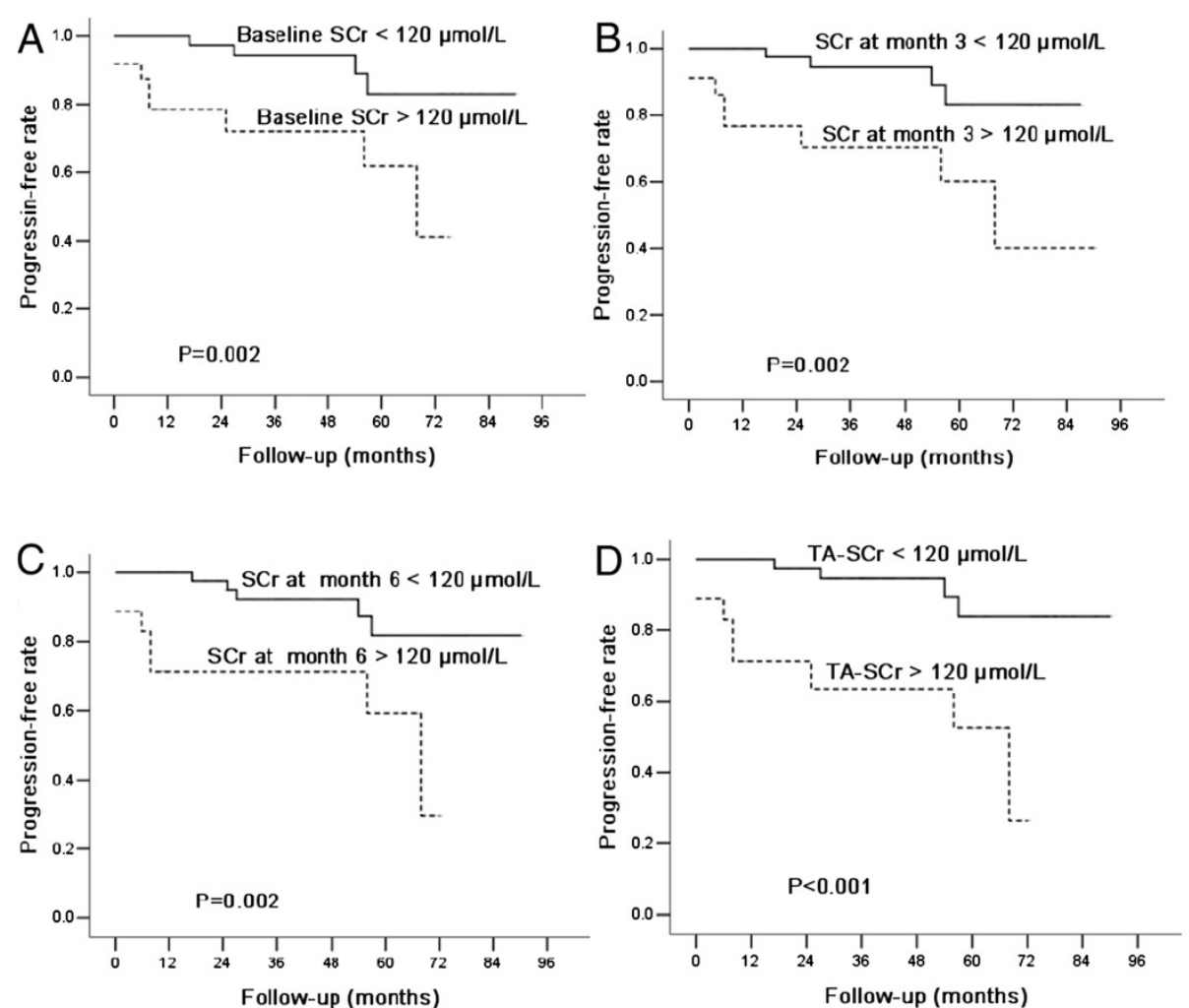

Figure 3 Kaplan-Meier plots of renal progression-free rates according to the SCr levels at diagnosis and during follow-up. (A) Baseline

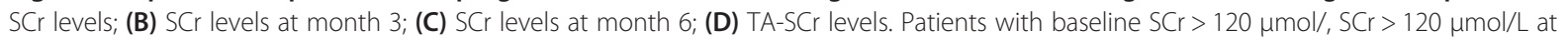
month 3, SCr $>120 \mu \mathrm{mol} / \mathrm{L}$ at month 6, or TA-SCr $>120 \mu \mathrm{mol} / \mathrm{L}$ had significantly reduced progression-free times $(\mathrm{P}<0.05)$. 
our study, we included a cohort of IgAN patients with mild proteinuria $(2 \mathrm{~g} / \mathrm{d})$; more than $70 \%$ of the patients had proteinuria $<1 \mathrm{~g} / \mathrm{d}$. After a multivariate Cox analysis, we were unable to provide clear evidence that the baseline UPE was associated with renal outcomes. However, we used the TA-UPE value to represent the average level of proteinuria during the follow-up and demonstrated that, while the TA-UPE was a strong predictor of renal function decline in patients with IgAN according to the univariate analysis, this parameter did not independently contribute to the risk in the multivariate models.

At the time of the renal biopsy, a higher level of SCr constituted an independent risk factor for long-term renal survival. Similar to prior reports $[2,4,5,8-10,16,26,27]$, we confirmed that the baseline $\mathrm{SCr}$ and eGFR were associated with renal progression among IgAN patients. We also found that the levels of SCr and the eGFR during followup were significantly different between the progression and non-progression patients. The TA-SCr value was an important independent risk factor for renal progression. These clinical parameters are among the most consistently reported predictors of progression, with similar findings observed across multiple cohorts [2,4,5,8-10,16,26,27].

Apart from the traditional risk factors, the ALB level during the follow-up was identified as a novel predictor for the progression of IgAN in this study. The adjusted multivariate Cox analysis model revealed that each $1 \mathrm{~g} / \mathrm{L}$ drop in the TA-ALB level was associated with a $14 \%$ increase in the risk of renal progression. The ROC curve indicated that the combination of the ALB at baseline and at follow-up has a more significant value in the prediction of renal outcome. According to the Kaplan-Meier analysis, we found that the patients with a TA-ALB $<38 \mathrm{~g} / \mathrm{L}$ had a 10.4-fold increased risk of progression compared with those with a TA-ALB $>38 \mathrm{~g} / \mathrm{L}$. These results demonstrate that patients are expected to have more unfavorable outcomes when the ALB level during follow-up is reduced to $<38 \mathrm{~g} / \mathrm{L}$. Therefore, we speculate that the optimal goal for TA-ALB among Chinese patients with IgAN should be $>38 \mathrm{~g} / \mathrm{L}$.

The ALB level is widely recognized as a biomarker of nutritional status and inflammation [30]. Hypoproteinemia is a common complication of CKD that has recently emerged as an important independent risk factor for kidney disease progression [2,31-36]. To our knowledge, our study is the first to identify ALB during a long-term follow-up as an independent risk factor for renal outcomes in IgAN patients. In a study based on a Chinese population, Chen $\mathrm{N}$ et al. [9] demonstrated an independent association of low baseline ALB levels with disease progression among patients with IgAN. Liu $\mathrm{ZH}$ et al. [2] found that baseline hypoproteinemia was an independent risk factor for an unfavorable IgAN outcome. In contrast to these studies, we did not find a relationship between baseline ALB and renal progression. Instead, our study provides strong support for the predictive value of ALB during a long-term follow-up for the assessment of renal progression risk. In this study, we used TA-ALB values to represent the average level of ALB during the follow-up and demonstrated that the TAALB value was a strong predictor of renal progression in patients with IgAN.

In addition, our findings did not confirm any independent association of blood pressure or pathological grading with renal survival. This finding is partly due to the fact that most patients had a normal arterial pressure level after the administration of anti-hypertensive agents, such as full doses of ACEis and/or ARBs. Furthermore, our study applied Lee's pathological classifications, which might have a limited predictive capacity compared with the Oxford classifications. The Oxford classification system is based upon four scores (mesangial hypercellularity, segmental glomerulosclerosis, endocapillary hypercellularity, and tubular atrophy/interstitial fibrosis) and constitutes an effective method for predicting renal outcomes $[37,38]$.

This study is unique in that it identified predictors for clinical outcomes among a pool of IgAN patients who achieved either a CR or a PR. In addition, this IgAN study also has a relatively longer follow-up time, involving more than 360 patients followed for 100 months. The strengths of this study include the large number of IgAN patients, a uniform therapy strategy, and the robust database, for which all the data were collected at regular 3-month intervals. However, the results of this study are limited by its location at a single medical center, and most of the patients recruited came from the southern regions of China. Furthermore, the renal function of most of the patients at the beginning of the trial period was good, and approximately $94 \%$ of the patients were in CKD stage 1-2. Therefore, the analyses had an inherent selection bias for disease severity and treatment choice. Thus, more studies are required to evaluate the progression of IgAN in patients under the current treatment regimen in the future.

\section{Conclusion}

In summary, our data clearly showed that the $\mathrm{TA}-\mathrm{SCr}$ and TA-ALB levels were associated with renal outcomes in patients achieving remission under the current therapeutic regimens for IgAN. Furthermore, ALB, especially during the follow-up, is a potential predictor for IgAN prognostic outcomes.

\footnotetext{
Abbreviations

ALB: Serum albumin; ALT: Glutamic-pyruvic transaminase; AST: Glutamic-oxaloacetic transaminase; BUN: Blood urea nitrogen; Ca: Serum calcium levels; C3: Complement 3 levels; CR: Complete remission; DBP: Diastolic blood pressure; eGFR: Estimated glomerular filtration rate; ESR: Erythrocyte
} 
sedimentation rate; ESRD: End stage renal disease; FBG: Fasting blood glucose; GN: Glomerulonephritis; Hb: Hemoglobin; HDL: High density lipoprotein; IgAN: IgA nephropathy; IgA: IgG, IgM, Serum immunoglobulin levels; LDL: Low density lipoprotein; PR: Partial remission; PLT: Thrombocytes; P: Serum inorganic phosphorus levels; RBC: Blood erythrocytes; SBP: Systolic blood pressure; SCr: Serum creatinine; TG: Triglyceride levels; TC: Serum total cholesterol levels: TA-ALB: Time-averaged serum albumin; TA-SCr: Time-averaged serum creatinine; TA-BUN: Time-averaged blood urea nitrogen; TA-eGFR: Time-averaged eGFR; TA-UPE: Time-averaged 24-h urinary protein excretion; UA: Serum uric acid; UPE: 24-h urinary protein excretion; URBC/HP: Hematuria; WBC: Blood leukocytes.

\section{Competing interests}

The authors report no conflicts of interest. The authors alone are responsible for the content and writing of this paper.

\section{Authors' contributions}

We thank all of the doctors at the Nephrology Department of Ren Ji Hospital in Shanghai, China for their work. Research idea and study design: SM, ZN and $Y Y$; data acquisition: YY, QW, LC, XC, MZ, YX and CQ; data analysis: SM, $Z N$ and $Y Y$; supervision or mentation :SM and $Z N$; manuscript writing: SM, ZN and YY. All authors read and approved the final manuscript

\section{Acknowledgements}

We thank all of the doctors at the Nephrology Department of Ren Ji Hospital in Shanghai, China for their work. This study was supported in part by the National Basic Research Program of China 973 Program No. 2012 CB517600 (No. 2012CB517602). The study was also sponsored by HongKong, Macao and Taiwan Science \& Technology Cooperation Program of China (2014DFT30090), the National Natural Science Foundation of China $(81102700,81373865)$ as well as by a grant $(12401906400,13401906100$ and 14140903200) from the Science and Technology Commission of Shanghai Municipality, China. Program ZYSNXD012-RC-ZXY017 from the Shanghai Health Bureau and grant ZZjdyx13049 from Shanghai municipal education committee were also included.

Received: 22 May 2014 Accepted: 4 July 2014

Published: 10 July 2014

\section{References}

1. Tatematsu M, Yasuda Y, Morita Y, Sakamoto I, Kurata K, Naruse T, Yamamoto R, Tsuboi N, Sato W, Imai E, Matsuo S, Maruyama S: Complete remission within 2 years predicts a good prognosis after methylprednisolone pulse therapy in patients with IgA nephropathy. Clin Exp Nephrol 2012, 16(6):883-891.

2. Le W, Liang S, Hu Y, Deng K, Bao H, Zeng C, Liu Z: Long-term renal survival and related risk factors in patients with IgA nephropathy: results from a cohort of 1155 cases in a Chinese adult population. Nephrol Dial Transplant 2012, 27(4):1479-1485.

3. Donadio JV, Grande JP: IgA nephropathy. N Eng/ J Med 2002, 347(10):738-748.

4. D'Amico G: Influence of clinical and histological features on actuarial renal survival in adult patients with idiopathic IgA nephropathy, membranous nephropathy, and membranoproliferative glomerulonephritis: survey of the recent literature. Am J Kidney Dis 1992, 20(4):315-323.

5. Koyama A, Igarashi M, Kobayashi M: Natural history and risk factors for immunoglobulin A nephropathy in Japan. Research Group on Progressive Renal Diseases. Am J Kidney Dis 1997, 29(4):526-532.

6. D'Amico G: Natural history of idiopathic IgA nephropathy and factors predictive of disease outcome. Semin Nephrol 2004, 24(3):179-196.

7. Disease K, Improving Global Outcomes (KDIGO) Glomerulonephritis Work Group: KDIGO Clinical Practice Guideline for Glomerulonephritis. Kidney Int Suppl 2012, 2(2):139-274.

8. Berthoux F, Mohey H, Laurent B, Mariat C, Afiani A, Thibaudin L: Predicting the risk for dialysis or death in IgA nephropathy. J Am Soc Nephrol 2011, 22(4):752-761.

9. Xie J, Kiryluk K, Wang W, Wang Z, Guo S, Shen P, Ren H, Pan X, Chen X, Zhang W, Li X, Shi H, Li Y, Gharavi AG, Chen N: Predicting progression of IgA nephropathy: new clinical progression risk score. PLoS One 2012, 7(6):e38904.

10. Rauta $V$, Gronhagen-Riska C: IgA nephropathy: from predicting progression to treatment. Duodecim 2006, 122(2):215-222.

11. Goto M, Wakai K, Kawamura T, Ando M, Endoh M, Tomino Y: A scoring system to predict renal outcome in IgA nephropathy: a nationwide 10-year prospective cohort study. Nephrol Dial Transplant 2009, 24(10):3068-3074.

12. Kaartinen K, Syrjanen J, Porsti I, Hurme M, Harmoinen A, Pasternack A, Huhtala $\mathrm{H}$, Mustonen J: Inflammatory markers and the progression of IgA glomerulonephritis. Nephrol Dial Transplant 2008, 23(4):1285-1290.

13. Wakai K, Kawamura T, Endoh M, Kojima M, Tomino Y, Tamakoshi A, Ohno Y, Inaba Y, Sakai H: A scoring system to predict renal outcome in IgA nephropathy: from a nationwide prospective study. Nephrol Dial Transplant 2006, 21(10):2800-2808.

14. D'Amico G, Minetti L, Ponticelli C, Fellin G, Ferrario F, di Barbiano Belgioioso G, Imbasciati E, Ragni A, Bertoli S, Fogazzi G: Prognostic indicators in idiopathic IgA mesangial nephropathy. Q J Med 1986, 59:363-378.

15. Radford MG Jr, Donadio JV Jr, Bergstralh EJ, Grande JP: Predicting renal outcome in IgA nephropathy. J Am Soc Nephrol 1997, 8(2):199-207.

16. D'Amico G: Natural history of idiopathic IgA nephropathy: role of clinical and histological prognostic factors. Am J Kidney Dis 2000, 36(2):227-237.

17. Geddes CC, Rauta V, Gronhagen-Riska C, Bartosik LP, Jardine AG, Ibels LS, Pei Y, Cattran DC: A tricontinental view of IgA nephropathy. Nephrol Dial Transplant 2003, 18(8):1541-1548.

18. Wakai K, Kawamura T, Matsuo S, Hotta N, Ohno Y: Risk factors for IgA nephropathy: a case-control study in Japan. Am J Kidney Dis 1999, 33(4):738-745.

19. Levey AS, Stevens LA, Schmid CH, Zhang YL, Castro AF 3rd, Feldman HI, Kusek JW, Eggers P, Van Lente F, Greene T, Coresh J, CKD-EPI (Chronic Kidney Disease Epidemiology Collaboration): A new equation to estimate glomerular filtration rate. Ann Intern Med 2009, 150(9):604-612.

20. Reich HN, Troyanov S, Scholey JW, Cattran DC: Remission of proteinuria improves prognosis in IgA nephropathy. J Am Soc Nephrol 2007, 18(12):3177-3183.

21. Ballardie FW, Roberts IS: Controlled prospective trial of prednisolone and cytotoxics in progressive IgA nephropathy. J Am Soc Nephrol 2002, 13(1):142-148

22. Lee HS, Lee MS, Lee SM, Lee SY, Lee ES, Lee EY, Park SY, Han JS, Kim S, Lee JS: Histological grading of IgA nephropathy predicting renal outcome: revisiting H.S. Lee's glomerular grading system. Nephrol Dial Transplant 2005, 20(2):342-348.

23. Yu HH, Chiang BL: Diagnosis and classification of IgA nephropathy. Autoimmun Rev 2014, 13(4-5):556-559.

24. Delclaux C, Jacquot C, Callard P, Kleinknecht D: Acute reversible renal failure with macroscopic haematuria in IgA nephropathy. Nephrol Dial Transplant 1993, 8(3):195-199.

25. Donadio JV, Bergstralh EJ, Grande JP, Rademcher DM: Proteinuria patterns and their association with subsequent end-stage renal disease in IgA nephropathy. Nephrol Dial Transplant 2002, 17(7):1197-1203.

26. Bartosik LP, Lajoie G, Sugar L, Cattran DC: Predicting progression in IgA nephropathy. Am J Kidney Dis 2001, 38(4):728-735.

27. Mackinnon B, Fraser EP, Cattran DC, Fox JG, Geddes CC: Validation of the Toronto formula to predict progression in IgA nephropathy. Nephron Clin Pract 2008, 109(3):C148-c153.

28. Yasuda Y, Horie A, Odani H, Iwase H, Hiki Y: Application of mass spectrometry to IgA nephropathy: structural and biological analyses of underglycosylated IgA1 molecules. Contrib Nephrol 2004, 141:170-188.

29. Vivante A, Afek A, Frenkel-Nir Y, Tzur D, Farfel A, Golan E, Chaiter Y, Shohat T, Skorecki K, Calderon-Margalit R: Persistent asymptomatic isolated microscopic hematuria in Israeli adolescents and young adults and risk for end-stage renal disease. JAMA 2011, 306(7):729-736.

30. De Feo P, Horber FF, Haymond MW: Meal stimulation of albumin synthesis: a significant contributor to whole body protein synthesis in humans. Am J Physiol 1992, 263(4 Pt 1):E794-E799.

31. Keane WF, Zhang Z, Lyle PA, Cooper ME, de Zeeuw D, Grunfeld JP, Lash JP, McGill JB, Mitch WE, Remuzzi G, Shahinfar S, Snapinn SM, Toto R, Brenner BM, RENAAL Study Investigators: Risk scores for predicting outcomes in patients with type 2 diabetes and nephropathy: the RENAAL study. Clin 」 Am Soc Nephrol 2006, 1(4):761-767.

32. Tangri N, Stevens LA, Griffith J, Tighiouart H, Djurdjev O, Naimark D, Levin A, Levey AS: A predictive model for progression of chronic kidney disease to kidney failure. JAMA 2011, 305(15):1553-1559.

33. Staples AO, Greenbaum LA, Smith JM, Gipson DS, Filler G, Warady BA, Martz K, Wong CS: Association between clinical risk factors and progression of chronic kidney disease in children. Clin J Am Soc Nephrol 2010, 5(12):2172-2179. 
34. Yokoyama H, Tomonaga O, Hirayama M, Ishii A, Takeda M, Babazono T, Ujihara U, Takahashi C, Omori Y: Predictors of the progression of diabetic nephropathy and the beneficial effect of angiotensin-converting enzyme inhibitors in NIDDM patients. Diabetologia 1997, 40(4):405-411.

35. Keane WF, Brenner BM, de Zeeuw D, Grunfeld JP, McGill J, Mitch WE, Ribeiro AB, Shahinfar S, Simpson RL, Snapinn SM, Toto R: The risk of developing end-stage renal disease in patients with type 2 diabetes and nephropathy: the RENAAL study. Kidney Int 2003, 63(4):1499-1507.

36. Leehey DJ, Kramer HJ, Daoud TM, Chatha MP, Isreb MA: Progression of kidney disease in type 2 diabetes - beyond blood pressure control: an observational study. BMC Nephrol 2005, 6:8.

37. Kang SH, Choi SR, Park HS, Lee JY, Sun IO, Hwang HS, Chung BH, Park CW, Yang CW, Kim YS, Choi YJ, Choi BS: The Oxford classification as a predictor of prognosis in patients with IgA nephropathy. Nephrol Dial Transplant 2012, 27(1):252-258.

38. Herzenberg AM, Fogo AB, Reich HN, Troyanov S, Bavbek N, Massat AE, Hunley TE, Hladunewich MA, Julian BA, Fervenza FC, Cattran DC: Validation of the Oxford classification of IgA nephropathy. Kidney Int 2011, 80(3):310-317.

doi:10.1186/1479-5876-12-194

Cite this article as: $\mathrm{Ni}$ et al:: Time-averaged albumin predicts the long-term prognosis of IgA nephropathy patients who achieved remission. Journal of Translational Medicine 2014 12:194.

\section{Submit your next manuscript to BioMed Central and take full advantage of:}

- Convenient online submission

- Thorough peer review

- No space constraints or color figure charges

- Immediate publication on acceptance

- Inclusion in PubMed, CAS, Scopus and Google Scholar

- Research which is freely available for redistribution 